


\section{Entscheidungen in Kirchensachen}

seit 1946

Begründet von

Prof. Dr. Dr. Carl Joseph Hering und Dr. Hubert Lentz

Herausgegeben von

Prof. Dr. Manfred Baldus

Vorsitzender Richter am Landgericht Köln a. D.

und

Prof. Dr. Stefan Muckel

Universitätsprofessor an der Universität zu Köln

in Verbindung mit dem Institut für Kirchenrecht und rheinische Kirchenrechtsgeschichte der Universität zu Köln 


\section{Entscheidungen in Kirchensachen}

seit 1946

67. Band

01.01.-30.06.2016

\section{DE GRUYTER}


ISBN 978-3-11-064418-0

e-ISBN (PDF) 978-3-11-064577-4

e-ISBN (EPUB) 978-3-11-064427-2

Library of Congress Control Number: 2019953364

Bibliografische Information der Deutschen Nationalbibliothek

Die Deutsche Nationalbibliothek verzeichnet diese Publikation in der Deutschen Nationalbibliografie; detaillierte bibliografische Daten sind im Internet über http://dnb.dnb.de abrufbar.

(C) 2020 Walter de Gruyter GmbH, Berlin/Boston

Druck und Bindung: $\mathrm{CPI}$ books $\mathrm{GmbH}$, Leck

www.degruyter.com 